\title{
LANNTING
}

\section{GEDUNG PERTUNJUKAN TEATER TAMAN BUDAYA BANJARBARU}

\author{
Bunga Suchie Ariani \\ Program Studi Arsitektur Fakultas Teknik Universitas Lambung Mangkurat \\ bungasuchiariani@gmail.com \\ Rudi Hartono \\ Program Studi Arsitektur Fakultas Teknik Universitas Lambung Mangkurat \\ rudihartono4497@gmail.com
}

\begin{abstract}
ABSTRAK
Perkembangan Teater di Kalimantan Selatan, khususnya Banjarbaru terus berkembang pesat. Hal ini tidak diimbangi dengan ketersediaan fasilitas dan sarana prasarana yang membuat aktivitas teater di Kalimantan Selatan cenderung tidak berkembang dengan baik. Sehingga pada tahun 2019, Provinsi Kalimantan Selatan (Pemprov Kalsel) bersama Taman Budaya Banjarmasin akan merencanakan pembangunan Gedung Pertunjukan Taman Budaya Baru yang berlokasi di kawasan Kantor Gubernur Kalimantan Selatan. Mereka menghendaki sebuah Gedung Pertunjukan Teater dengan sistem pencahayaan yang memadai serta ruang penunjang yang fungsional dan akses terarah. Selain itu, mereka menghendaki agar Gedung Pertunjukan di Area Taman Budaya Banjarbaru bisa menjadi Landmark Kota Banjarbaru dengan nuansa Arsitektur Kalimantan Selatan. Oleh karena itu metode yang cocok dipilih adalah Metode Arsitektur Ikonik dimana dapat diwujudkan dengan 3 prinsip desain berdasarkan tinjauan konsep, yakni: (a) Elemen Tradisional (traditional element), (b) Elemen Berulang (continuous rhythm), dan (c) Elemen Fungsional (functional element). Ketiga elemen ini diwujudkan dengan menganalisis sudut pandang, sirkulasi, material, warna dan tekstur pada interior dan eksterior agar menghasilkan desain Gedung Pertunjukan yang baik sesuai kebutuhan klien.
\end{abstract}

Kata Kunci: Gedung Pertunjukan Teater, Taman Budaya, Arsitektur Ikonik, Banjarbaru

\begin{abstract}
The development of the Theater in South Kalimantan, especially Banjarbaru continues to grow rapidly. This is not appropriate with the lack of existing facilities and infrastructure makes theatre activities in South Kalimantan not well developed. Therefore in 2019, South Kalimantan Provincial Government together with Banjarmasin Cultural Park will plan the construction of Theatre Performance Building in a New Cultural Park Area which is located in the Governor's Office Area of South Kalimantan. They want Theater Performance Building with an adequate lighting system and functional support space with directional access. Beside that, they want this Performance Building to become a Landmark in Banjarbaru City with the nuance of South Kalimantan Architecture. Therefore, the suitable method chosen is the Iconic Architectural Method which can be realized with 3 design principles based on a concept review, there are: (a) Traditional Elements, (b) Continuous Rhythm, and (c) Functional Elements. These three elements are realized by analyzing the point of view, circulation, material, color and texture of the interior and exterior in order to produce a good performance building design according to the client's needs.
\end{abstract}

Keywords: Theater Performance Building, Cultural Park, Iconic Architecture, Banjarbaru 


\section{PENDAHULUAN}

Pada tahun 2019, Pemerintah Provinsi Kalsel (Pemprov Kalsel) bersama Taman Budaya Banjarmasin akan merencanakan Gedung Pertunjukan Teater Taman Budaya yang merupakan bagian dari perencanaan Masterplan Komplek Pemprov Kalsel di Banjarbaru dengan Sumber Dana dari APBD Provinsi Kalsel. Gedung Pertunjukan ini diharapkan dapat memfasilitasi berbagai macam pertunjukan khususnya teater yang terkoneksi dengan taman budaya baru sebagai pusat informasi budaya di Kalimantan Selatan. Bangunan ini kedepannya akan berada di bawah tanggung jawab UPTD Taman Budaya Kalsel dalam pengelolaannya.

Penduduk Kalimantan Selatan memiliki apresiasi yang tinggi terhadap seni pertunjukan, terbukti dari kegiatan seni pertunjukan di Balairung sari yang tidak pernah sepi pengunjung. Frekuensi Pertunjukan yang diselenggarakan di gedung ini terbilang cukup sering yakni 3-4 kali dalam sebulan bahkan lebih. Selain itu banyak pula pertunjukan teater yang hanya diselenggarakan di aula yang sangat tidak memenuhi standar sebuah pertunjukan. Alhasil penonton pun merasa kurang nyaman saat menonton pertunjukan. Minimnya sarana dan prasarana yang ada membuat aktivitas teater di Kalimantan Selatan cenderung tidak berkembang dengan baik. Hal ini tidaklah wajar mengingat minat dan perkembangan teater di Banjarbaru yang terus berkembang pesat.

Kalimantan Selatan sendiri memiliki potensi seniman teater dan peminat teater dalam jumlah yang cukup banyak. Hal ini terbukti dengan adanya komunitas-komunitas teater yang meliputi komunitas teater yang didominasi oleh anak sekolah dan mahasiswa. Terdapat pula Forum Komunitas Pekerja Seni Kampus (FKPSK) yang merupakan perkumpulan dari berbagai lembaga seni yang ada di berbagai kampus di Kota Banjarbaru dan Banjarmasin. Hal ini membuktikan bahwa Kalimantan Selatan memiliki potensi seniman di bidang teater yang cukup besar. Terdapat 25 Komunitas Teater Kampus yang tergabung dalam FKPSK dan tersebar di berbagai Prodi Universitas di Banjarbaru dan Banjarmasin.

Kegiatan Pertunjukan di Kalimantan Selatan seringkali diselenggarakan pada suatu tempat yakni di Gedung Balairung Sari, akan tetapi kondisi gedung ini banyak memiliki kekurangan dan belum bisa dikatakan sebagai gedung pertunjukan yang baik baik dari segi akustik, pencahayaan, penghawaan maupun kapasitasnya. Sistem akustik pada Gedung Pertunjukan ini kurang memadai sehingga suara dari dalam masih terdengar keluar gedung. Selain itu sistem penghawaannya pun kurang merata sehingga banyak penonton yang merasa kurang nyaman saat menonton pertunjukan. Jalur akses penonton pun kurang jelas dan tidak sesuai standar. Akses loading barang pun terkendala, karena pintu yang kurang besar, dan terkendala kesediaan alat untuk memindahkan barang berat dan besar. Selain itu Kapasitas Gedung Pertunjukan ini hanya menampung 300 orang, hal itu sangat tidak sesuai dengan jumlah peminat seni pertunjukan yang ada di Kalimantan Selatan.

Dari hasil wawancara pada tanggal 13 Maret 2019 dengan Ibu Suharyanti selaku Kepala Taman Budaya Banjarmasin, dapat diambil kesimpulan bahwa Gedung Pertunjukan yang dikehendaki oleh klien adalah Gedung pertunjukan yang sesuai standar dan bisa menggambarkan adegan nyata dalam sebuah stage sesuai keinginan penggarap. Pemprov Kalsel menghendaki sebuah Gedung Pertunjukan Teater berkapasitas 900-1200 orang dengan sistem pencahayaan yang memadai serta ruang penunjang yang fungsional dan akses terarah. Selain itu, Pemprov Kalsel menghendaki agar Gedung Pertunjukan di area Taman Budaya Baru bisa menjadi 
Landmark Kota Banjarbaru dengan bentuk ornamen, dan material yang bernuansa Arsitektur Kalimantan Selatan. Target Penampil di Gedung Pertunjukan ini yakni dari kalangan amatir sampai profesional.

\section{TINJAUAN PUSTAKA}

\section{A. Tinjauan Persyaratan Gedung Pertunjukan}

\section{a. Standar Tempat Duduk}

Menurut Mills (1976:32) standar tempat duduk auditorium gedung pertunjukan berdasarkan kapasitasnya terbagi menjadi 4 yakni seperti pada tabel berikut:

Tabel 1 Standar Tempat Duduk Auditorium

\begin{tabular}{|c|c|}
\hline KAPASITAS & $\begin{array}{l}\text { JUMLAH TEMPAT } \\
\text { DUDUK }\end{array}$ \\
\hline Very Large & $\begin{array}{l}1500 \text { atau lebih tempat } \\
\text { duduk }\end{array}$ \\
\hline Large & $900-1500$ tempat duduk \\
\hline Medium & 500-900 tempat duduk \\
\hline Small & $\begin{array}{l}\text { kurang dari } 500 \text { tempat } \\
\text { duduk }\end{array}$ \\
\hline
\end{tabular}

Sumber: Mills, 1976: 32

Sedangkan untuk ukuran auditorium ditentukan oleh jumlah penonton, sehingga didapat luar area auditorium yang diperlukan dengan perhitungan standar $\geq 0$ $5 \mathrm{~m}^{2} /$ penonton.

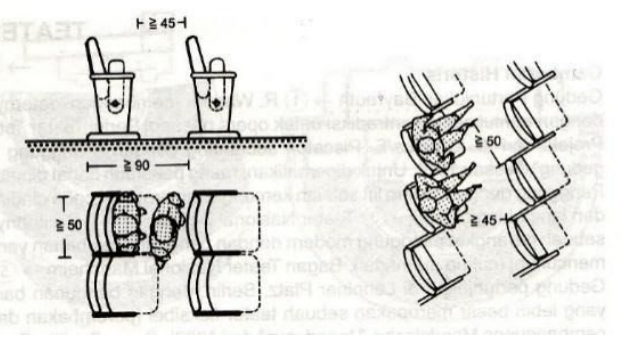

Gambar 1 Ukuran Ruang Penonton Sumber: Neufert, 2002: 138

\section{b. Proporsi Ruang Penonton}

Desain auditorium gedung pertunjukan harus dibuat sedekat mungkin dengan sumber bunyi dengan mengurangi jarak tempuh bunyi. Hal ini dapat disiasati dengan penambahan balkon sehingga penonton tetap dapat menyaksikan pertunjukan dengan jelas (Doelle, 1990: 54).

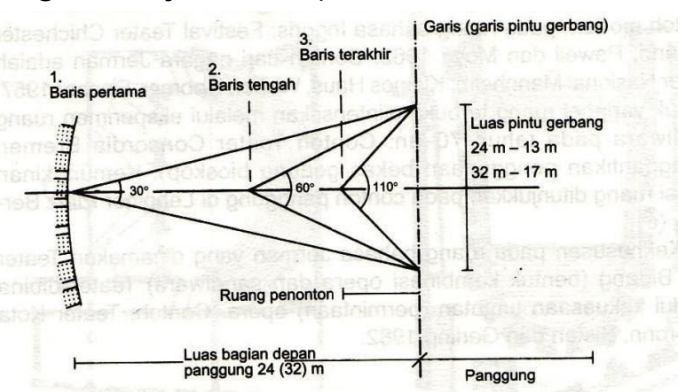

Gambar 2 Proporsi Ruang Penonton Sumber: Doelle, 1990: 54

- Jarak maksimal untuk melihat perubahan ekspresi wajah dengan baik adalah 30 meter dari ujung belakang panggung ke baris tempat duduk terakhir.

- Sudut pandang yang baik, dimana mudah menggerakan mata tanpa gerakan kepala adalah sekitar $30^{\circ}$.

- Sudut pandang yang baik, dimana mudah menggerakan mata dan sedikit menggerakan kepala adalah sekitar $60^{\circ}$

- Maksimal sudut pandang tanpa gerakan kepala kira-kira $110^{\circ}$. Artinya pada bidang ini orang bisa menangkap hampir semua jalannya peristiwa

\section{c. Memperhatikan Sightline dan Kemiringan Lantai}

Sightline dirancang sebaik mungkin untuk kenyamanan penonton dari segi visual dan pendengaran. Berikut beberapa aspek sightline sebagai berikut:

- $\mathbf{P}$ adalah titik acuan terbawah sudut pandang penonton agar dapat melihat pertunjukan dengan jelas. Untuk opera, musik dan drama, titik $P$ berada maksimal $600 \mathrm{~mm}$ di atas panggung.

- HD adalah jarak horizontal antara mata penonton ke penonton lain dalam satu baris dengan ukuran antara 760 sampai $1,150 \mathrm{~mm}$.

- EH adalah tinggi rata-rata mata saat penonton duduk di kursi yaitu $1.120 \mathrm{~mm}$. 
- $\quad$ E adalah jarak antara kepala ke pusat mata, dengan dimensi minimal $125 \mathrm{~mm}$ agar pandangan tidak terhalang oleh kepala orang di barisan depan.

- D adalah jarak dari titik P ke mata penonton di barisan paling depan. Apabila baris pertama semakin dekat dengan panggung, maka jarak $\mathrm{D}$ akan semakin curam

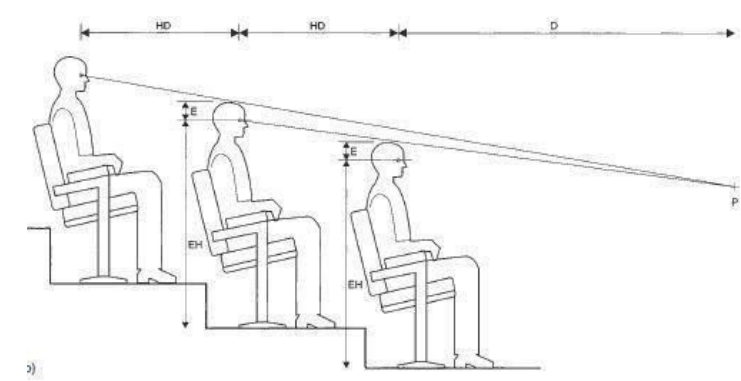

Gambar 3 Perhitungan Sightline

Sumber: Strong, 2010

Tinggi tempat duduk dibuat sesuai dengan perhitungan sightline pada penjelasan sebelumnya. Perhitungan Sightline ini berlaku pada semua tempat duduk baik di tribun bawah maupun balkon. Biasanya area tempat duduk dibuat bertangga (tribun) dengan pertimbangan kenyamanan dan keselamatan dimana kemiringan tidak boleh lebih dari 1:8 atau $30^{\circ}$.

\section{d. Sirkulasi Ruang Penonton (Gangways)}

Gangways merupakan akses sirkulasi terbesar dalam auditorium bagi penonton dengan lebar minimum $1100 \mathrm{~mm}$. Perhitungan sightline harus diperhatikan, agar orang yang melewati gang tidak mengganggu penonton.

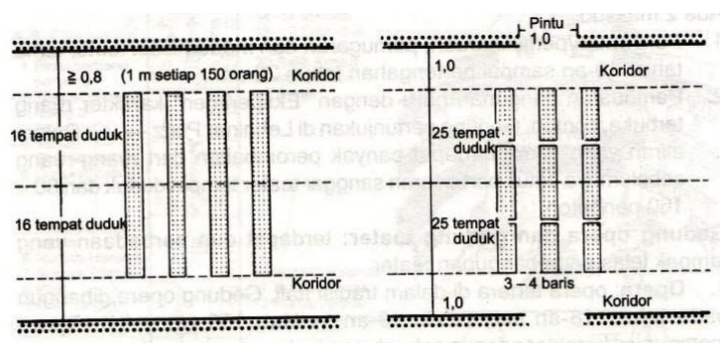

\section{Gambar 4 Sirkulasi Ruang Penonton} Sumber: Neufert, 2002: 138

Spasi antar baris (clearway) merupakan jarak antara bagian depan kursi di belakang dengan sandaran kursi yang ada di depannya yang berjarak antara 400-500 $\mathrm{mm}$. Clearway ini harus diperhatikan agar penonton nyaman baik saat mencapai tempat duduk maupun saat menonton pertunjukan.

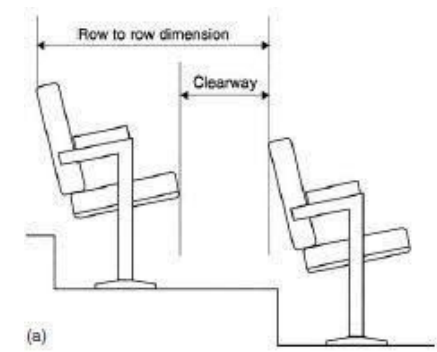

Gambar 5 Spasi antar Baris Penonton Sumber: Strong, 2010

\section{e. Menaikan Sumber Bunyi}

Menurut Doelle (1990: 54) sumber bunyi harus dinaikkan agar aliran gelombang bunyi dapat merambat secara langsung kepada setiap pendengar

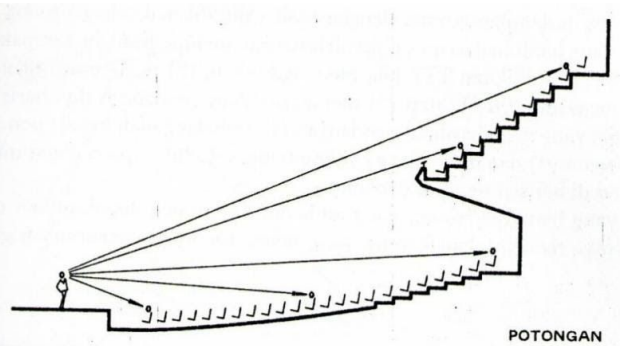

Gambar 6 Menaikan sumber bunyi Sumber: Doelle 1990: 54

\section{f. Sumber Bunyi dikelilingi Lapisan Pemantul Bunyi}

Menurut Doelle (1990: 56) Sumber bunyi harus dikelilingi oleh permukaan yang dapat memantulkan bunyi seperti plywood, gypsum board, plexiglass, dan lain sebagainya dalam jumlah yang cukup banyak dan besar agar bunyi dapat dipantulkan dan sampai ke penonton yang terjauh sekalipun.

Mills (1976:26) berpendapat bahwa salah satu upaya untuk memperkuat bunyi 
dari panggung adalah dengan menyediakan pemantul di atas bagian depan auditorium agar bunyi secara langsung terdengar ke tempat duduk paling belakang

Jadi dapat disimpulkan bahwa lapisan pemantul bunyi yang paling tepat yakni bisa diterapkan pada plafon dan dinding auditorium.

Sehingga perlu ditempatkan banyak pemantul suara dengan cara digantung ataupun ditempelkan seperti pada gambar dibawah ini:

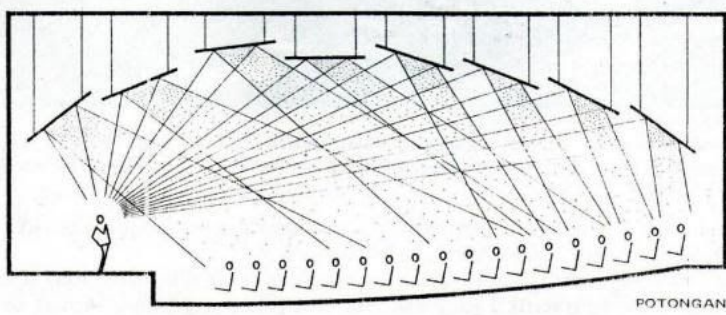

Gambar 7 Lapisan Pemantul Bunyi pada Plafon Sumber: Doelle, 1990:56

Dari gambar di atas dapat disimpulkan bahwa apabila langit-langit pemantul suara diletakkan di tempat dan sudut yang tepat, maka akan menghasilkan pemantulan suara yang baik dan merata ke seluruh penonton. Fungsi dari pemantul suara ini yakni dapat memantulkan dan memperkuat suara yang efektif secara akustik sehingga mampu menghasilkan kualitas suara yang diinginkan dan menjangkau ke tempat duduk terjauh sekalipun.

\section{g. Menghindari Pemantul Bunyi yang Saling Berhadapan}

Disarankan bentuk permukaan pemantul bunyi dibuat miring terutama pada plafon yang berada di atas sumber bunyi. Hal ini agar bunyi langsung menyebar ke arah penonton (Doelle, 1990: 57). Selain itu, hindari permukaan yang paralel (vertikal atau horizontal), terutama yang berdekatan dengan sumber bunyi agar menghilangkan resiko pemantulan kembali ke sumber bunyi.

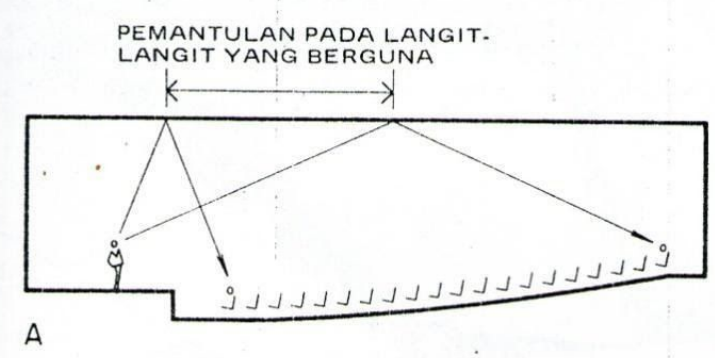

Gambar 8 Pemantulan Suara pada Plafon Datar Sumber: Doelle, 1990:57

Bentuk plafond yang datar seperti gambar di atas sangat tidak dianjurkan karena mengakibat-kan plafon tidak berfungsi sebagai pemantul bunyi sehingga bunyi yang diterima penonton paling belakang menjadi sangat lemah

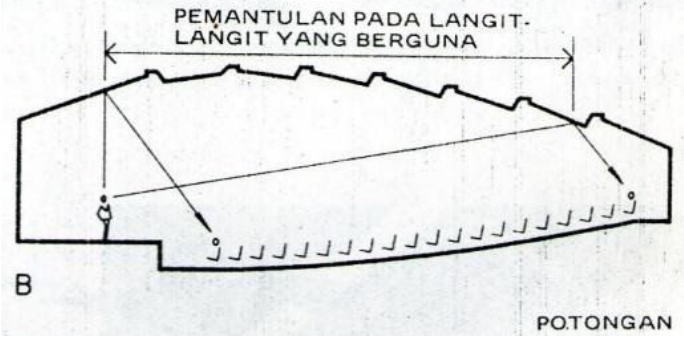

Gambar 9 Pemantulan Suara pada Plafon Zigzag Sumber: Doelle, 1990:57

Sebaliknya, bentuk plafon seperti gambar diatas yang tidak beraturan dan dimiringkan sangat dianjurkan. Hal ini karena bunyi langsung (direct sound) dapat dipantulkan dan disebarkan secara merata dan efektif ke arah penonton hingga ke tempat duduk terjauh sekalipun.

\section{h. Menempatkan Penonton di Area yang Paling Menguntungkan}

Menurut Doelle (1990:57), penonton harus dibuat berada di area yang paling menguntungkan, baik dalam hal mendengar maupun melihat. Selain itu, daerah tempat duduk yang sangat lebar harus dihindari. 


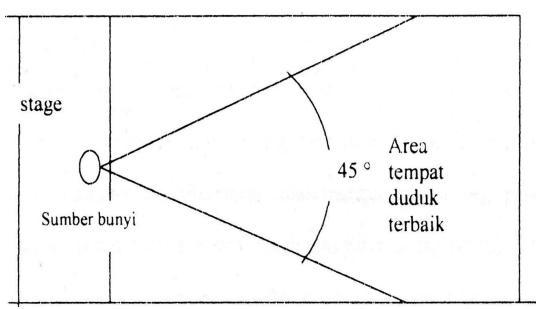

Gambar 10 Ukuran Ruang Penonton

Sumber: Doelle, 1990: 57

Gambar di atas menjelaskan bahwa area sumbu longitudinal yang merupakan posisi melihat dan mendengar terbaik berada pada sudut $45^{\circ}$ dari sumber bunyi. Oleh karena itu, area ini harus diefektifkan untuk meletakkan tempat duduk. Selain itu, hindari perletakan lorong sirkulasi di area ini.

\section{B. Tinjauan Sistem Pencahayaan}

\section{Adanya Sistem Pencahayaan Area Auditorium}

Fungsi sistem pencahayaan dalam seni pertunjukan bukan hanya sebagai penerangan dalam ruangan saja, tetapi juga sebagai estetika dan penambah rasa dalam setiap gerakan yang dilakukan pemain. Secara umum, tata cahaya yang ada dan bisa diterapkan pada Gedung Pertunjukan Teater Taman Budaya ini adalah:

Tabel 2 Jenis Lampu pada Area Auditorium

\begin{tabular}{|c|c|}
\hline POSISI & KETERANGAN \\
\hline $\begin{array}{l}\text { ed } \\
\text { orium }\end{array}$ & \begin{tabular}{l}
\multicolumn{1}{c}{ Pencahayaan ini } \\
diperlukan \\
keperluan pencahayaan \\
langsung dan dapat \\
dinyalakan saat sebelum \\
memulai dan setelah \\
selesai pertunjukan.
\end{tabular} \\
\hline $\begin{array}{l}\text { Lampu Led } \\
\text { pada Tangga }\end{array}$ & $\begin{array}{l}\text { Pencahayaan ini } \\
\text { sangat penting agar jalur } \\
\text { sirkulasi dan area tempat } \\
\text { duduk terlihat jelas. Selain } \\
\text { itu pencahayaan ini pun } \\
\text { dapat dijadikan sebagai } \\
\text { jalur evakuasi jika terjadi } \\
\text { kebakaran. }\end{array}$ \\
\hline
\end{tabular}

Sumber: Analisis Penulis, 2020

\section{Adanya Sistem Pencahayaan Area Panggung}

Pencahayaan merupakan bagian yang cukup penting dalam teater. Untuk mengekspresikan sebuah pertunjukan, diperlukan teknik pencahayaan yang berbeda pada setiap adegannya. Fungsi utama dari tata cahaya ini adalah agar dapat memastikan bahwa tidak ada bayangan yang mengganggu saat pertunjukan berlangsung (Santosa Eko, 2008: 331). Oleh karena itu diperlukan studi tentang posisi dan jenis lampu yang berada di area panggung pertunjukan. berikut analisisnya:

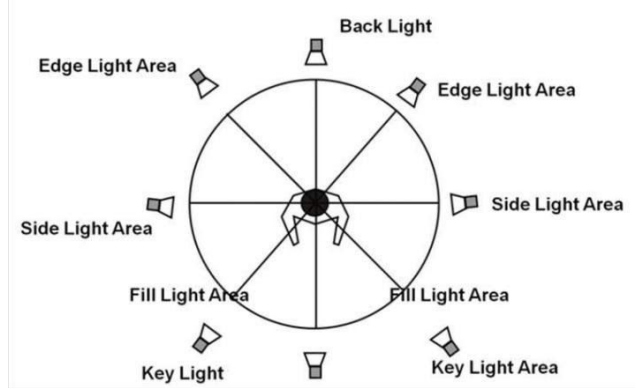

Gambar 11 Posisi Pencahayaan Panggung Sumber: Santosa, 2008: 331

\section{- Key Light}

Key Light yakni pencahayaan paling utama dan dominan yang langsung diarahkan ke objek atau pemain.

\section{- Fill Light}

Fill Light yakni pencahayaan pengisi, fungsinya untuk menghilangkan bayangan objek yang disebabkan oleh key light

\section{- Front Light}

Cahaya dari depan pentas yang berfungsi untuk membuat wajah pemain dapat terlihat dengan jelas dari arah penonton.

\section{- Overhead}

Cahaya yang bersumber dari atas kepala pemain. Fungsinya yakni untuk mencahayai panggung dari atas. 


\section{- Side Light}

Cahaya yang bersumber dari samping kiri dan kanan panggung. Tujuannya agar tidak ada bayangan yang mengganggu saat objek bergerak.

\section{- Back Light}

Cahaya yang bersumber dari belakang pemain yang dapat membuat ilusi seakan-akan pemain tidak menempel pada backdrop karena bagian atas pemain lebih terang dibanding yang lain.

\section{METODE PERANCANGAN}

\section{A. Metode Penyelesaian Masalah}

Metode yang akan digunakan dalam menyelesaikan permasalahan pada Gedung Pertunjukan Teater Taman Budaya ini adalah sebuah metode yang dapat memunculkan citra dari kebudayaan Kalimantan Selatan pada bangunan. Sehingga metode yang paling tepat dipilih adalah Metode Arsitektur Ikonik. Icon dalam Kamus Inggris-Indonesia berarti suatu tanda atau penanda, maka Iconic dapat diartikan sesuatu yang mempunyai tanda, atau objek yang menjadi penanda di suatu daerah.

Arsitektur Ikonik sebagai penanda tempat erat kaitannya dengan arsitektur vernakular dimana bentuk bangunannya biasanya hadir secara terus-menerus dalam waktu yang sangat lama, dan tak jarang hadir pula di berbagai daerah meski berjauhan. Peniruan berulang terus-menerus pada akhirnya akan mengakibatkan terbentuknya image dalam masyarakat bahwa bentuk tersebut ideal dan perlu dipertahankan, sehingga akhirnya terbentuk tipologi bangunan serupa.

\section{Penerapan Metode Arsitektur Ikonik}

Dalam perancangan Gedung Pertunjukan Teater Taman Budaya ini menerapkan metode Arsitektur Ikonik. Penggunaan metode ini dimaksudkan untuk menghadirkan suatu bangunan Gedung
Pertunjukan Teater yang dapat menjadi Icon Kota Banjarbaru.

Berdasarkan latar belakang metode yang dipaparkan sebelumnya dapat diambil kesimpulan bahwa pendekatan arsitektur ikonik adalah suatu metode 'baru' desain dalam hal penciptaan bentuk dengan cara mengacu (meniru) bentukan yang telah ada sebelumnya yang dianggap ideal dan perlu dipertahankan. Dimana perancangan ini diharapkan dapat mewujudkan desain bangunan yang dapat menjadi Ikon (penanda) Kota Banjarbaru dan Provinsi Kalimantan Selatan.

Berdasarkan pemahaman dari berbagai sumber pada tinjauan pustaka, dapat disimpulkan bahwa prinsip desain Arsitektur Ikonik, yakni:

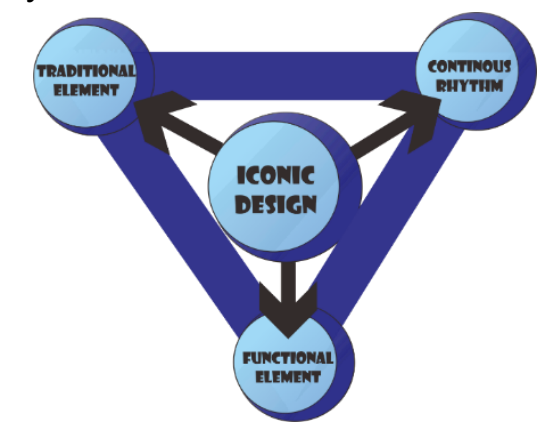

Gambar 12 Metode Arsitektur Ikonik Sumber: Analisis Penulis, 2020

\section{PEMBAHASAN}

\section{A. Konsep Program}

Rancangan Gedung Pertunjukan Teater Taman Budaya ini diharapkan dapat mewujudkan desain bangunan yang dapat menjadi Icon (penanda) Kota Banjarbaru dan Provinsi Kalimantan Selatan. Untuk mewujudkan prinsip tersebut maka ada beberapa aspek yang dapat menjadi acuan desain Gedung Pertunjukan Teater Taman Budaya, yakni: 


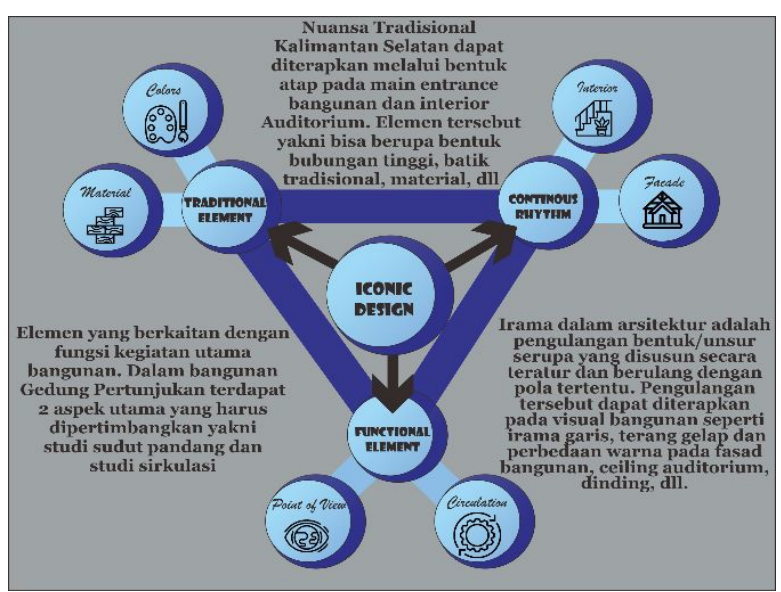

Gambar 13 Konsep Program

Sumber: Analisis Penulis, 2020

1. Penerapan Elemen Fungsional

a. Konsep Sudut Pandang

Tabel 3 Sudut Pandang Horizontal

\section{SUDUT PANDANG HORIZONTAL}

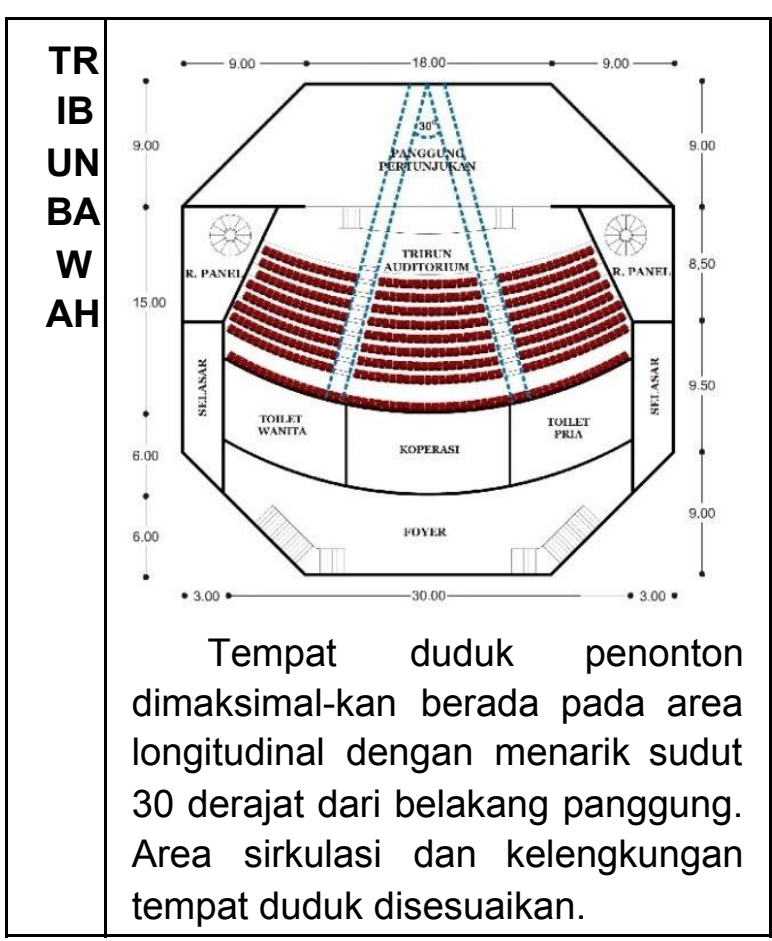

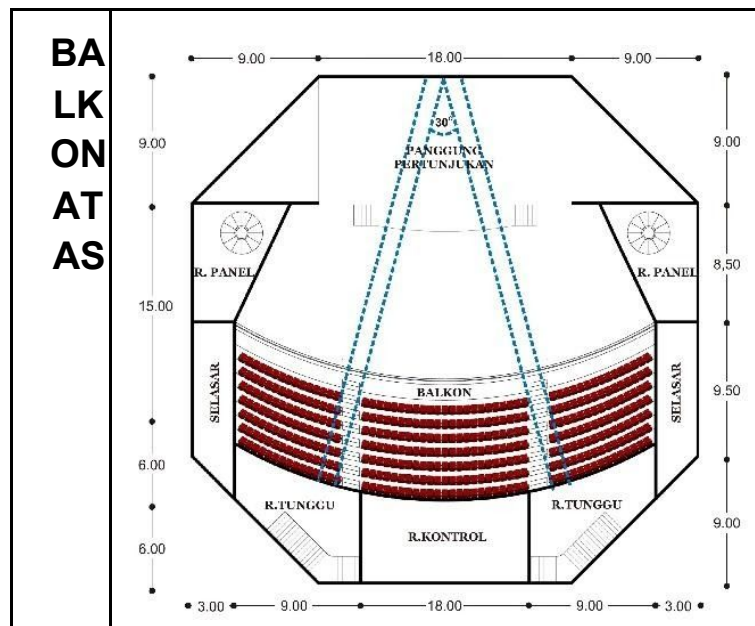

Tempat duduk penonton area balkon dimaksimal-kan berada pada area longitudinal dengan menarik sudut 30 derajat dari belakang panggung. Area sirkulasi dan kelengkungan tempat duduk disesuaikan. Letak balkon berada tepat di atas R. Kontrol'

Sumber: Analisis Penulis, 2020 berdasarkan Appleton, 2008

Tabel 4 Sudut Pandang Vertikal

SUDUT PANDANG VERTIKAL

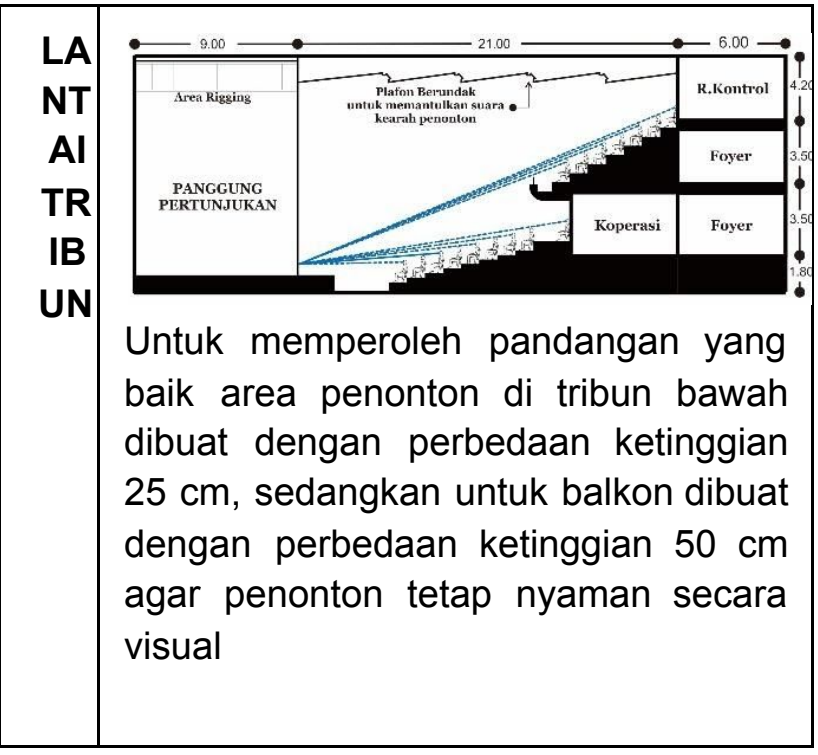




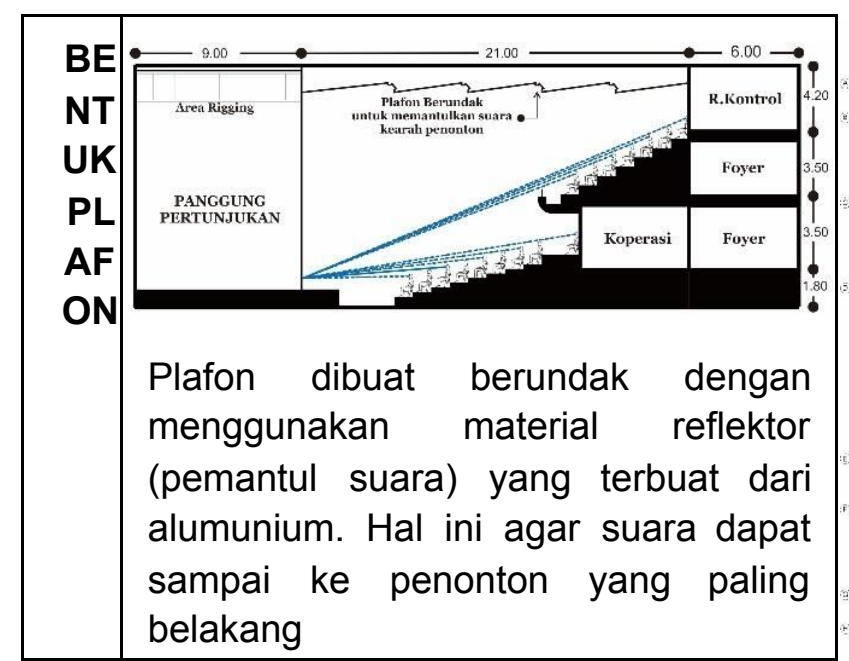

Sumber: Analisis Penulis, 2020 berdasarkan Appleton, 2008

\section{b. Konsep Sirkulasi}

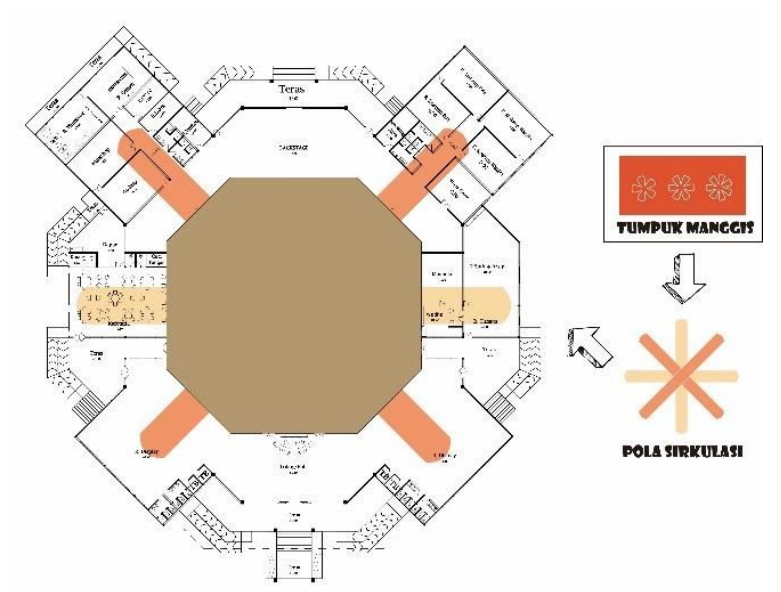

Gambar 14 Konsep Sirkulasi Denah

Sumber: Analisis Penulis, 2020

Motif Batik Sasirangan Tampuk Manggis melambangkan sebuah kejujuran yang harus ditanamkan pada setiap generasi. Bentuk motif ini sangat cocok diambil sebagai acuan sirkulasi denah Gedung Pertunjukan Teater ini karena aktivitasnya bersifat memusat ke auditorium. Bentuk denah disiasati dengan memecah sirkulasi secara diagonal di bagian depan dan belakang bangunan sesuai zonanya sehingga seluruh aktivitas gedung pertunjukan berjalan secara efektif dan efisien.

\section{c. Output Denah, Potongan dan Tampak berdasarkan Konsep}

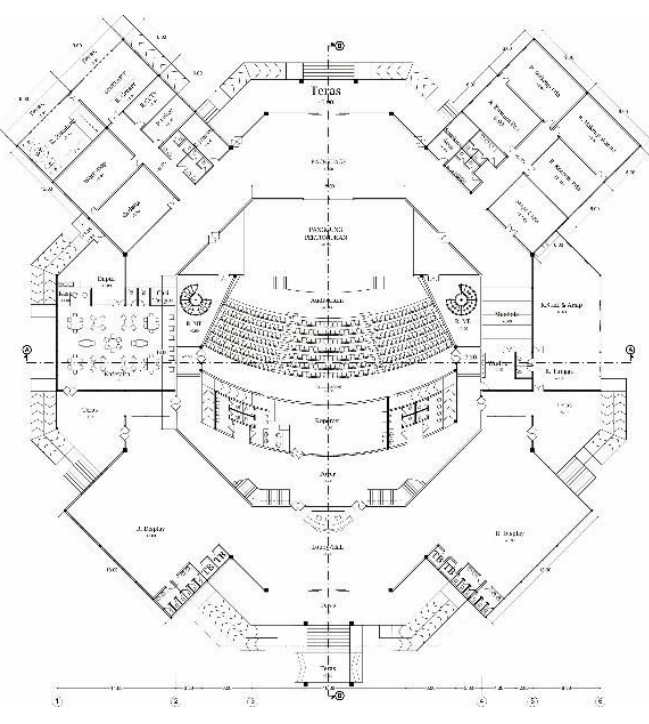

Gambar 15 Denah Lantai 1

Sumber: Analisis Penulis, 2020

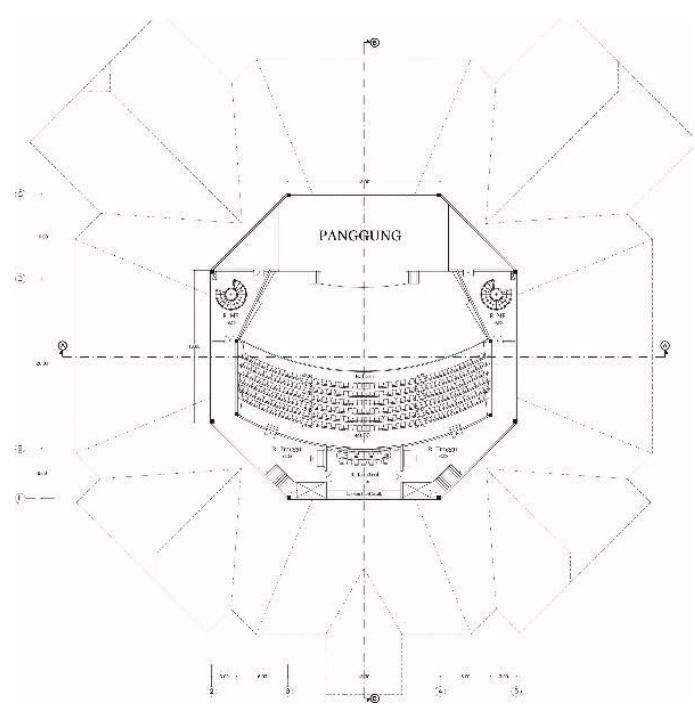

Gambar 16 Denah Lantai 3

Sumber: Analisis Penulis, 2020

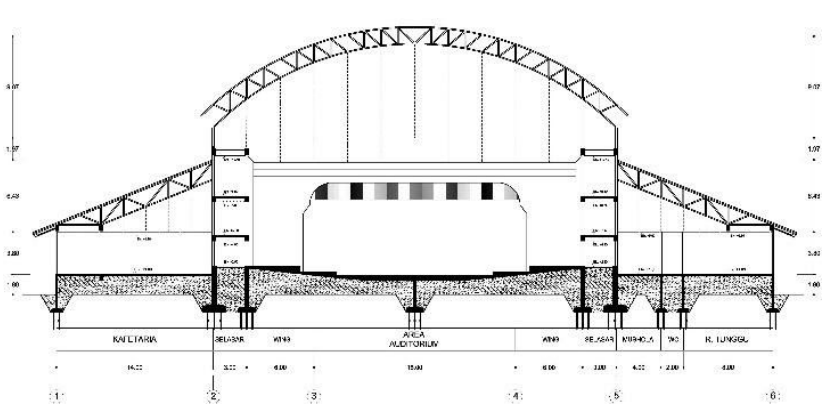

Gambar 17 Potongan A-A

Sumber: Analisis Penulis, 2020 


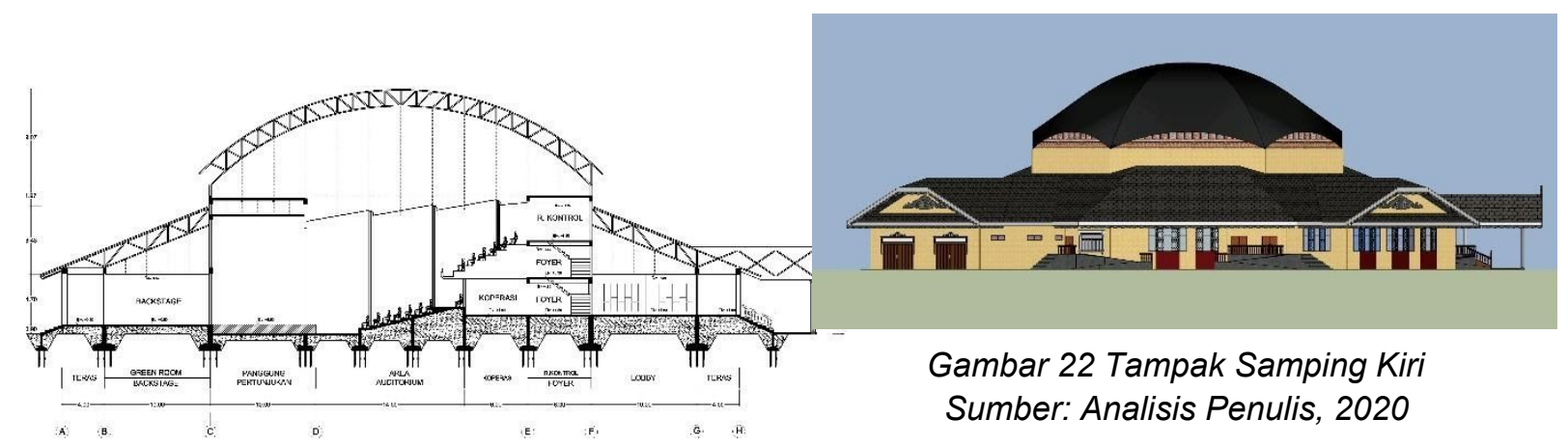

Gambar 18 Potongan $B-B$

Sumber: Analisis Penulis, 2020

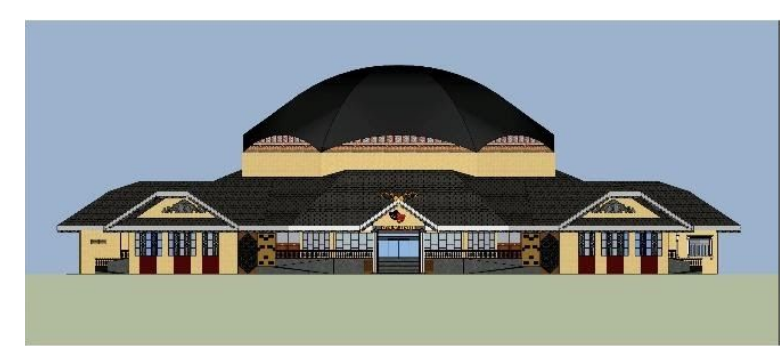

\section{Penerapan Konsep pada Interior}

\section{a. Konsep Interior Auditorium}

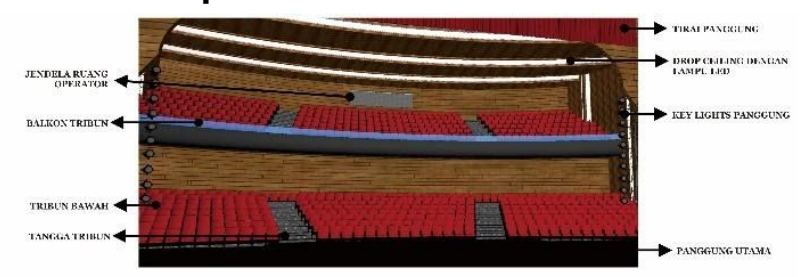

Gambar 19 Tampak Depan

Sumber: Analisis Penulis, 2020

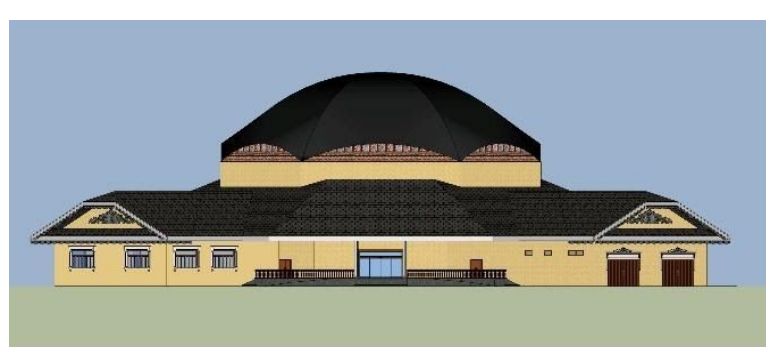

Gambar 20 Tampak Belakang

Sumber: Analisis Penulis, 2020
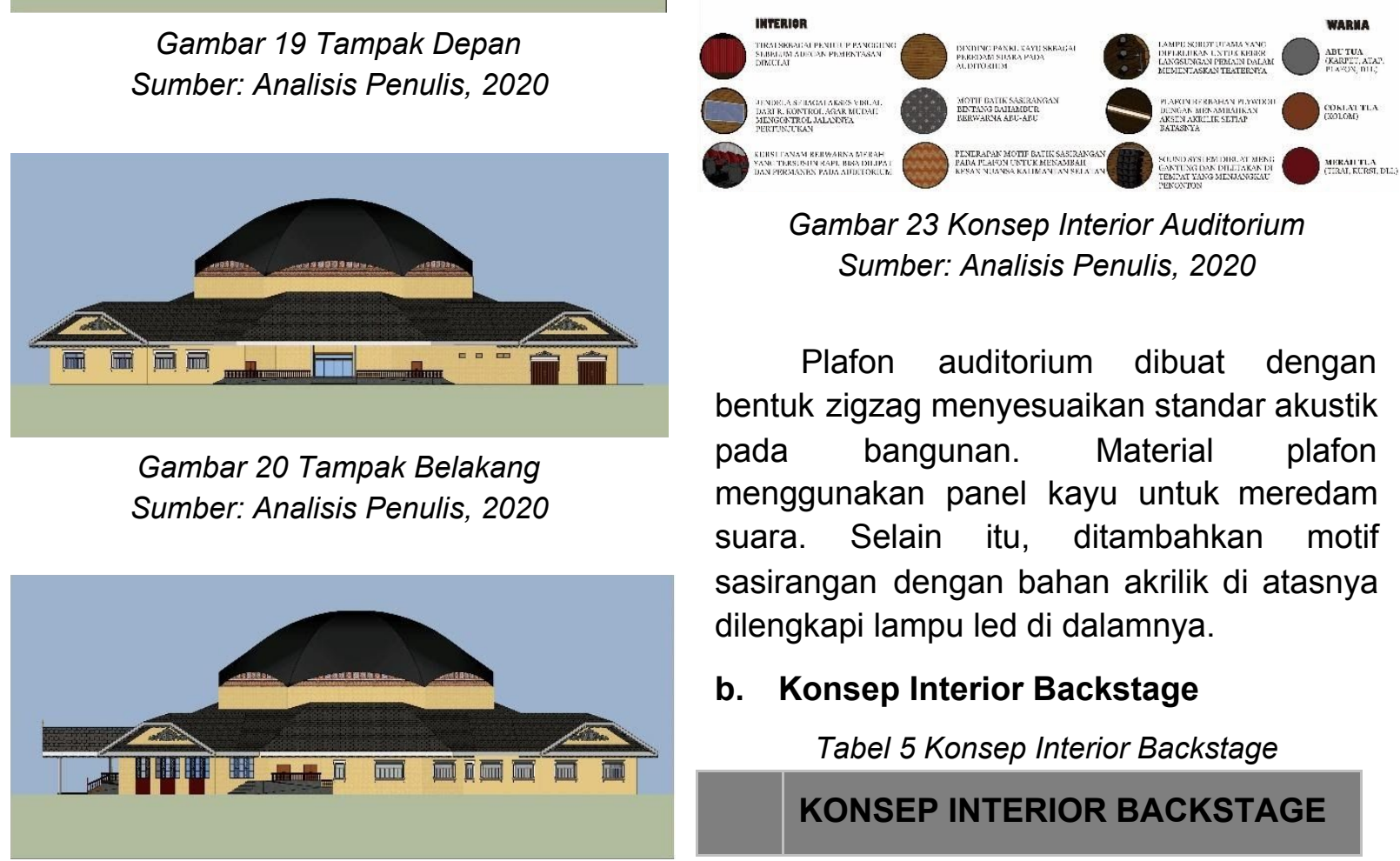

Gambar 23 Konsep Interior Auditorium Sumber: Analisis Penulis, 2020

Plafon auditorium dibuat dengan bentuk zigzag menyesuaikan standar akustik pada bangunan. Material plafon menggunakan panel kayu untuk meredam suara. Selain itu, ditambahkan motif sasirangan dengan bahan akrilik di atasnya dilengkapi lampu led di dalamnya.

\section{b. Konsep Interior Backstage}

Tabel 5 Konsep Interior Backstage

\section{KONSEP INTERIOR BACKSTAGE}

Gambar 21 Tampak Samping Kanan Sumber: Analisis Penulis, 2020

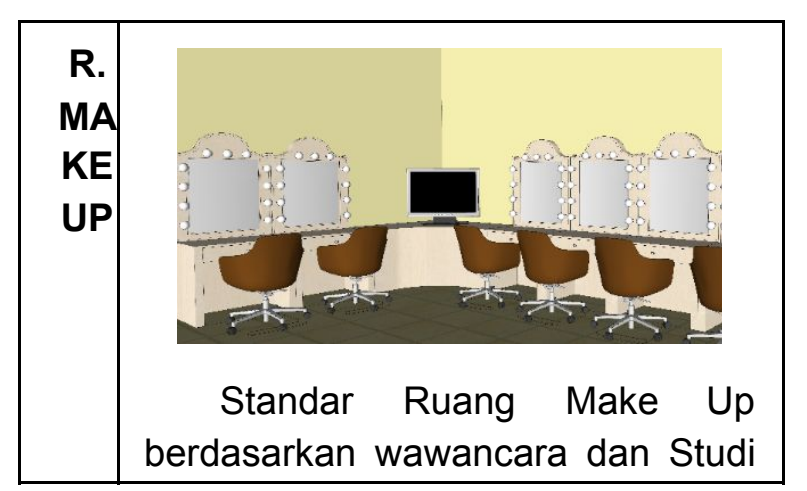




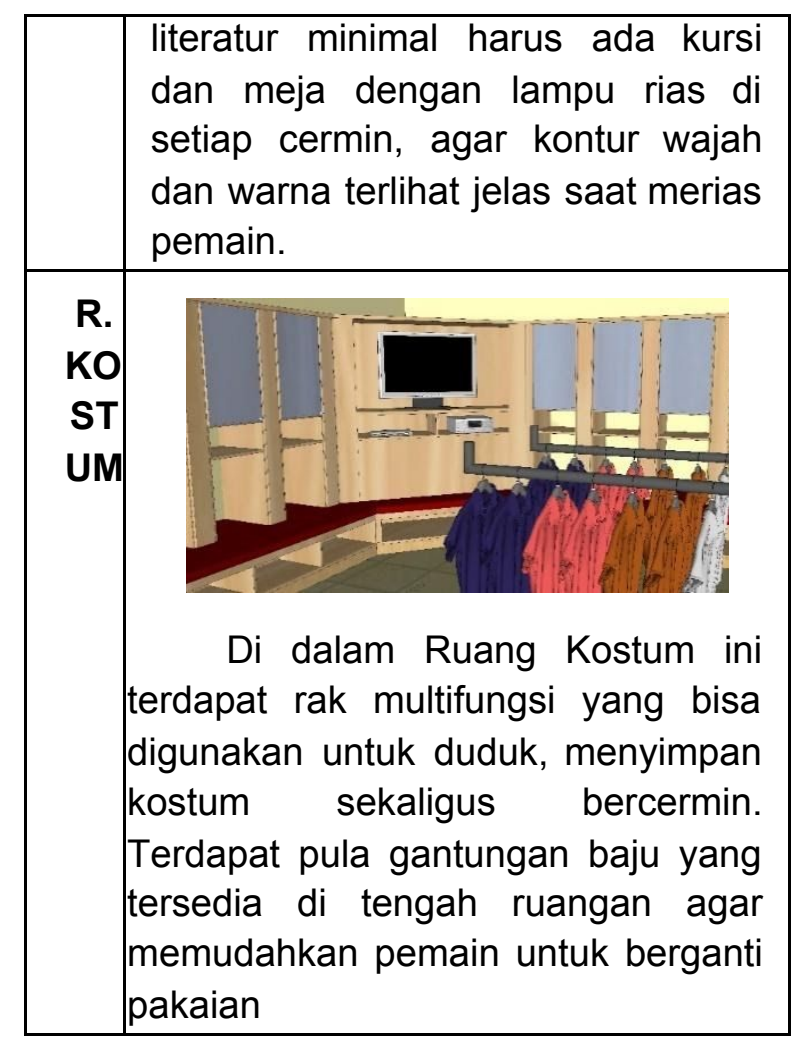

Sumber: Analisis Penulis, 2020 berdasarkan Appleton, 2008

\section{Penerapan Konsep pada Eksterior \\ a. Konsep Tapak}

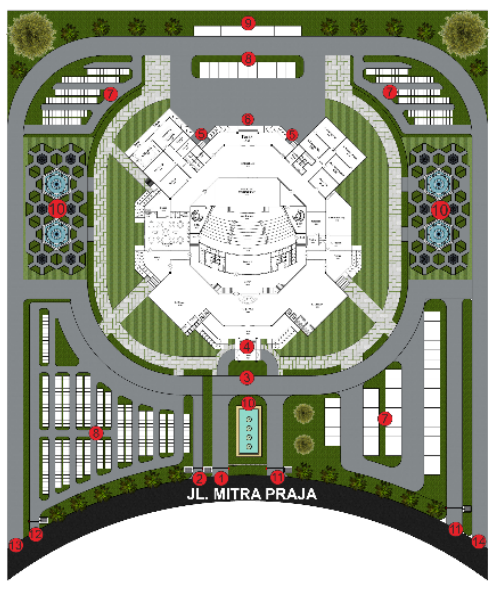

KETERANGAN

1 Gerbang MAsuk Mobil

2) GERBANG MASUK MOTOR

3) DROP OFF

(4) main entrance

(5) ENTRANCE LOADING Dock

- ENTRANCE PEMAIN DAN CREW

(7) PARKIR MOTOR

(c) PARKIR MOBIL

(9) parkir bis

- area taman

(1) gerbang Keluar mobil

2 gerbang Keluar motor - Gerbang MAsUK PEMAIN DAN GERBANG KELU LOADING DOCK

Gambar 24 Konsep Tapak

Sumber: Analisis Penulis, 2020

Berdasarkan Analisis, Akses Entrance

terbagi menjadi 2 yakni:

\section{- Jalur masuk Pengunjung}

Area Parkir Mobil dan Motor Pengunjung diletakkan di depan, agar memudahkan dekat dengan entrance bangunan. Akses sirkulasinya untuk motor dimulai dari depan tengah sebelah kiri, menuju parkiran motor lalu keluar dari sebelah kiri site. Sedangkan akses sirkulasi mobil dimulai dari depan tengah, menuju parkiran motor lalu keluar ke jalur exit di samping gerbang keluar mobil pemain

\section{- Jalur masuk Pemain, Loading Dock}

Area Parkir Pemain dan Staff, Bis, dan Loading dock diletakkan di area belakang. Akses sirkulasinya dimulai dari depan sebelah kiri, ke parkiran, melingkar mengelilingi bangunan, lalu keluar melalui depan kanan site.

\section{b. Konsep Bentuk Fasad}

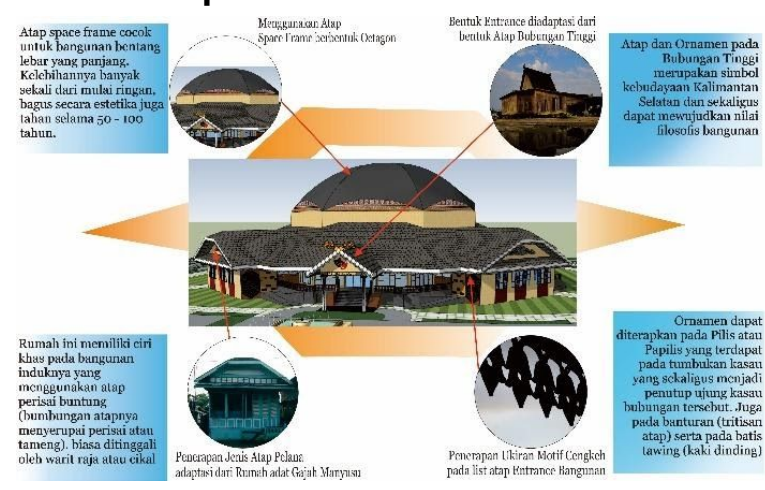

Gambar 25 Konsep Fasad

Sumber: Analisis Penulis, 2020

\section{c. Perspektif Eksterior}

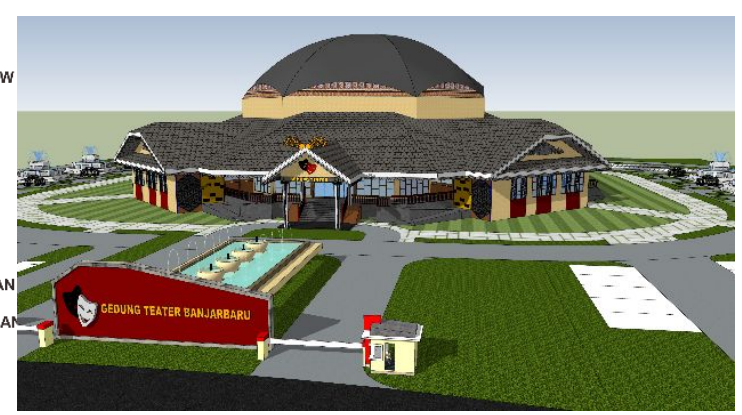

Gambar 26 Perspektif dari Gerbang Sumber: Analisis Penulis, 2020 


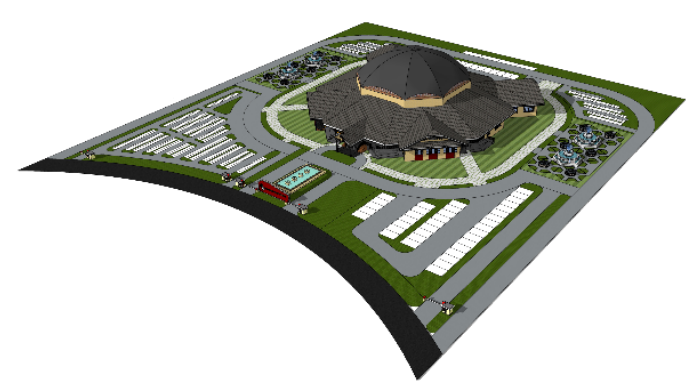

Gambar 27 Perspektif Mata Burung

Sumber: Analisis Penulis, 2020

\section{KESIMPULAN}

Pada tahun 2019, Pemerintah Provinsi Kalsel, bersama Taman Budaya Banjarmasin akan merencanakan pembangunan Gedung Pertunjukan Taman Budaya Baru yang berlokasi di Kawasan Perkantoran Gubernur Kalimantan Selatan. Gedung Pertunjukan ini diharapkan dapat memfasilitasi berbagai macam pertunjukan khususnya teater yang terkoneksi dengan taman budaya baru sebagai pusat informasi budaya di Kalimantan Selatan.

Pemprov Kalsel menghendaki sebuah Gedung Pertunjukan Teater berkapasitas 900-1200 orang dengan sistem pencahayaan yang memadai serta ruang penunjang yang fungsional dan akses terarah. Selain itu, Pemprov Kalsel menghendaki agar Gedung Pertunjukan di area Taman Budaya Baru bisa menjadi Landmark Kota Banjarbaru dengan bentuk ornamen, dan material yang bernuansa Arsitektur Kalimantan Selatan.

Metode yang dipilih untuk mewujudkan Gedung Pertunjukan Taman Budaya sebagai Landmark Kota yang bernuansa Kalimantan Selatan adalah Arsitektur Ikonik. Prinsip Arsitektur Ikonik merupakan arsitektur yang meniru (mengacu) bentukan yang ada sebelumnya (tradisi) kemudian dianggap ideal dan perlu dipertahankan serta memodifikasi bentuk menjadi lebih atraktif dan menarik. Untuk mewujudkan prinsip tersebut maka ada beberapa aspek yang dapat menjadi acuan desain Gedung Pertunjukan Teater Taman Budaya, yakni:

a. Elemen Tradisional (traditional element)

b. Elemen Berulang (continuous rhythm)

c. Elemen Fungsional (functional element)

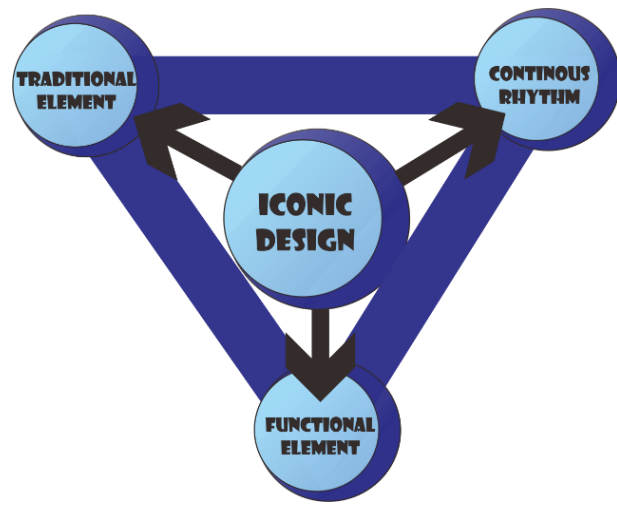

Gambar 28 Prinsip Metode Arsitektur Ikonik Sumber: Analisis Penulis, 2020

\section{DAFTAR PUSTAKA}

Appleton, lan. 2008. Building for the Performing Arts. London: The Press Ltd.

Doelle, Leslie E. 1990. Akustik Lingkungan. Jakarta: Erlangga

Mills, Association of British Theatre Technicians. 1972. Theatre Planning. London: The Architectural Press Ltd.

Neufert, Ernst. 2002. Data Arsitek Jilid II Edisi 33. Jakarta: Erlangga

Santosa, Eko. 2008. Seni Teater Jilid 2. Jakarta. Direktorat Pembinaan SMK

Strong Judith. 2010. Theatre Building a Design Guide 